\title{
Peer Interaction, Cognitive Conflict and Anxiety on a Grammar Awareness Course for Language Teachers
}

\begin{abstract}
This study explored some MA students' perceptions of a Grammar Awareness course for language teachers. The aim was to understand how group tasks might help students build Grammar Awareness. Two cohorts of students were surveyed and interviewed. In this paper the survey responses are discussed in some depth. While the first cohort was left to organize their groups as they wished, the second cohort used a more structured, cooperative framework. The paper compares the two cohorts, and novice and experienced teachers, to see 1/ whether novice and experienced teachers benefitted equally or differentially and $2 /$ what effect the changes had. Central features of the pedagogy were the use of authentic texts and open ended group tasks. The intention was to create cognitive conflict as an impetus for engagement and in depth negotiations, leading to knowledge creation. The novice teachers on the whole found tasks and texts more difficult, and had greater problems focusing on the task. The more structured group work led to increased task focus in both groups, and more active participation by the TESOL students, and thus appeared to facilitate engagement with the language, but anxiety was high and increased for the TESOL students in the second cohort.
\end{abstract}

Key words: anxiety; authentic text; grammar awareness; cognitive conflict; collaborative learning; cooperative group work.

\section{Introduction}

This paper discusses student perceptions of a Grammar Awareness course which sought to maximize their active involvement with tasks requiring linguistic analysis. The course is a required component of a programme at an English university leading to MA TESOL, or MA Applied Linguistics \& TESOL (henceforth MA AL). Two cohorts were included in the study, one in 2008-9 and one in 2009-10. The course was evaluated each time, and changes made to the course design on the basis of the first evaluation. A questionnaire survey and interviews were used to find out to what extent the different elements of the course helped foster engagement likely to meet the immediate course aims (enhanced Grammar Awareness) and enrich the participants' own teaching after the degree.

An assumption behind the course design was that language teachers need to be able to do much more with text than read and understand it. They need to understand and be able to explain how the writer's choice of grammatical form, in the given context, contributes to the meaning of the text; identify available grammatical alternatives, and their effect on meaning; identify and correct ungrammatical or inappropriate choices (errors); assess the level of difficulty of the text; identify specific grammatical challenges and, if appropriate, devise grammar learning tasks on it. If they can do this confidently, and especially if they can deal with authentic text (text written for purposes other than language education), they are much 
less dependent on published course materials in their teaching, and better able to adapt to particular learner needs and contexts. For these reasons, workshop tasks were designed based on authentic texts, and pitched at a level which it was thought would be challenging but manageable.

Previous experience led the researcher to expect that the tasks would provoke some anxiety, for some students because they were aware of not having much grammar knowledge and for others, who were confident in this area, because their knowledge would sometimes not match the authentic language they were asked to discuss. How the workshop tasks were perceived, including the anxiety they engendered, will be discussed below.

As this was a piece of practitioner research I, the researcher, was also responsible for designing and teaching the course and cannot claim to be objective in the positivist sense. It was, however, not in my interest to underestimate or fail to uncover any problems in its design or delivery as I was most likely to continue teaching the course. The purpose of the study was to discover to what extent first the original and then the modified course design facilitated engagement with language (Svalberg 2009) in the form of engagement with specific grammar tasks.

Svalberg (2009) showed how engagement with language leads to enhanced Language Awareness (LA) ${ }^{1}$, which in turn becomes a resource for further engagement in a cyclical process, creating what Dillenbourg et al (1996) call "a spiral of causality" (p.3).

Engagement with language was defined as follows:

In the context of language learning and use, Engagement with language ... is a cognitive and/or social, and/or affective, state and process in which the learner is the agent and language is object (and sometimes vehicle). (p.247)

The following table attempted to formulate what characterizes an engaged individual.

Table 1. Key characteristics of engagement with language (Svalberg 2009, p.246)

\begin{tabular}{|c|c|c|c|}
\hline & Cognitive & Affective & Social \\
\hline \multirow[t]{2}{*}{$\begin{array}{l}\text { Key } \\
\text { characteristics }\end{array}$} & $\begin{array}{l}\text { State: heightened } \\
\text { alertness,focused } \\
\text { attention }\end{array}$ & $\begin{array}{l}\text { State: Positive } \\
\text { orientation towards the } \\
\text { language, the } \\
\text { interlocutor and what } \\
\text { they represent }\end{array}$ & $\begin{array}{l}\text { State: behavioural } \\
\text { readiness to interact }\end{array}$ \\
\hline & $\begin{array}{l}\text { Process:Focused } \\
\text { reflection and problem } \\
\text { solving }\end{array}$ & $\begin{array}{l}\text { Process: willingness to } \\
\text { interact with the } \\
\text { language and/or the } \\
\text { interlocutor is } \\
\text { maintained/heightened }\end{array}$ & $\begin{array}{l}\text { Process: initiating and } \\
\text { maintaining } \\
\text { interaction }\end{array}$ \\
\hline
\end{tabular}


The focus of the study was thus not on the effect of the course in terms of outcomes, but on the learning process itself. The approach sought to allow the students' voices to steer the study, through their survey replies and interviews. Below only the survey will be discussed.

The course and the students involved in the study will be described in the following section, and the course pedagogy will then be put into a context of existing theoretical frameworks. The perceptions of the students in the first cohort will be presented to serve as a baseline against which the second cohort's evaluation can be compared. Finally, tentative conclusions will be drawn and some implications for future practice and research suggested.

\section{The Course}

The course investigated is a 15 credit MA course called Grammar Awareness which, together with a Phonology course of the same length, make up the mandatory core element Descriptions of English. The duration of the grammar component is seven weeks. It is taught over fourteen hours divided into seven 50 min lectures, plus seven 50 min group work seminars (workshops). There is also a Virtual Learning Environment (VLE) component consisting of activities, tasks and additional materials.

A number of aims are stated in the course specification. By the end of the course the students should be better able to analyze, reflect on and talk about English Grammar; to reflect on implications for teaching; to understand learners' grammar needs; to help learners improve their grammar use.

A wide variety of backgrounds are normally represented on the course, which caters for the two streams already mentioned: MA AL, which requires two years prior language teaching experience; and MA TESOL, which does not have any such pre-requisite. There was thus a mix of experienced and novice teachers. This was reflected in the age rage, with the generally younger MA TESOL students often joining the course straight after obtaining their first degree. Table 2 below shows number of participants in the two streams per cohort, and number of survey returns. 
Table 2. Number of participants by specialization and cohort

\begin{tabular}{|c|c|c|c|c|}
\hline & $\overline{\text { MA AL }}$ & MA TESOL & Total & Survey Returns \\
\hline $\begin{array}{l}\text { C1 } \\
(2008-2009)\end{array}$ & $\mathrm{M} 2 / \mathrm{F} 18=20$ & $\mathrm{M} 11 / \mathrm{F} 13=24$ & $\mathrm{M} 13 / \mathrm{F} 31=44$ & $\begin{array}{ll}\text { MA AL } & 17 \\
\text { MA TESOL } & \frac{14}{31}\end{array}$ \\
\hline $\begin{array}{l}\text { C2 } \\
(2009-2010)\end{array}$ & M 3/F $14=17$ & M4/F31=35 & $\mathrm{M} 7 / \mathrm{F} 45=52$ & $\begin{array}{ll}\text { MA AL } & 17 \\
\text { MA TESOL } & \underline{30} \\
7\end{array}$ \\
\hline
\end{tabular}

The majority of students were female, and the novice teachers outnumbered the experienced teachers. Among the experienced teachers, five in the first cohort $(\mathrm{C} 1)$ and three in the second (C2) had 10 years experience or more. Excluding these, the AL students had on average 4 years experience while the TESOL students had typically just completed their first degrees. The students' prior knowledge was not measured ${ }^{2}$. Results on the final, written test (one component of the final module assessment) were roughly comparable for the two strands in $\mathrm{C} 1$, but there was a clear difference in achievement in $\mathrm{C} 2$, with the TESOL students being the weaker (Appendix A). Student grades on the programme as a whole also indicated that there were a few particularly weak students in the C2 TESOL group.

\section{Course Pedagogy}

There were two delivery formats: lecture and workshop. The former provided input which the students could use in carrying out the workshop tasks. For example, lecture six dealt with modality (modal verbs; conditionals) and lecture seven with information structure (e.g. clefts, pseudo-clefts; theme-rheme structure) and these were also the topics of the sixth and sevenths workshop tasks. There was a set grammar course book ${ }^{3}$ to complement the material devised specifically for the course. The structure of the course is shown in Table 3.

Table 3. The Grammar Awareness Course structure

\begin{tabular}{ll}
\hline Stages & Material in VLE \\
\hline Pre-Lecture & Pre-session activity \\
\hline Lecture $(50 \mathrm{~min})$ & Power point handout \\
& Worksheet \\
\hline Post-Lecture/ & Pre-session activity Key \\
Pre-Workshop & Workshop Task \\
\hline Workshop (50 min) & Workshop Task \\
\hline
\end{tabular}

In 2008-2009 (C1) the lecture was immediately followed by the workshop in a two hour block. In 2009-2010 (C2), due to a shortage of suitably sized rooms for the rising student numbers and consequent time-tabling problems, there was one day between lecture and workshop. Each four-stage set focused on a different grammar topic. For each topic, the four stages with corresponding materials followed sequentially as in the above table. 
Primarily to enhance the students' own Grammar Awareness, but also to add to the pedagogic options available to them in their own classrooms, a collaborative awareness raising approach was applied. It conformed, essentially, to Borg's model of an LA approach to language teacher education (Borg 1994, p.62, building on Wright \& Bolitho 1993). Its view of learning is essentially social constructivist and a central component is engagement with language. Svalberg (2007) summarized its features:

1. It involves an ONGOING INVESTIGATION of language as a dynamic phenomenon rather than awareness of a fixed body of established facts.

2. It involves learners in TALKING ANALYTICALLY ABOUT language, often to each other.

3. It considers the INVOLVEMENT of learners in exploration and discovery essential.

4. It aims to develop not only the learners' knowledge about and understanding of language but also their LEARNING SKILLS, thus promoting learner independence.

5. The aim is to involve learners on both a COGNITIVE and an AFFECTIVE level.

(Svalberg 2007, p.290-291)

The view of language articulated in (1) above, in which learners become investigators, informed the entire Grammar Awareness course, including the lecture and workshop components. It was underpinned by the view that contrary to what many teachers and students believe, grammar rules are partial and imperfect representations of what they attempt to describe. As Blyth (1997, p.52) points out: "teachers frequently mistake the rule itself for what it actually represents - the mental process of the speaker". Overall, grammar was presented as a flexible resource for the realization of speakers' intended meanings. The underlying philosophy was thus essentially functionalist, inspired by the Hallidayan school of thought (e.g. Halliday 1985), but the terminology and classifications were largely mainstream (e.g. as in the work by Randolph Quirk, Sydney Greenbaum and others) to match most participants' background knowledge and probable requirements in future teaching contexts.

The Grammar Awareness pedagogy just described can be characterized as 'post-method', as the term has been defined in a series of papers by Kumaravadivelu (1994, 2001, 2006). The author uses the term to indicate that new language learning/teaching methods have invariably delivered less than expected, leading to the realization that given the varied language learning contexts and needs, the ideal method will never materialize. Kumaravadivelu (1994) acknowledged that teachers, in fact, tend to adapt to their context in an eclectic manner. This, however, can result in "unsystematic, unprincipled, and uncritical pedagogy" (p.30) according to the author, who instead puts forward a framework of strategies for 'principled pragmatism' in language teaching and teacher education. It consists of ten macrostrategies, six of which will be referred to below: (1) maximize learning opportunities, 
(2) facilitate negotiated interaction, (3) activate intuitive heuristics, (4) foster language awareness, (5) contextualize linguistic input, (6) promote learner autonomy (p.32).

Grammar Awareness is one type of Language Awareness (LA), which Kumaravadivelu (1994) recommends developing in learners (strategy 4) along with their intuitive language sensitivity (strategy 3). While Kumaravadivelu treats LA and sensitivity as distinct, the usual LA definition ${ }^{1}$ includes the latter as one aspect of the former, perhaps because intuitions have the potential to be formulated and reflected on. To help the students on the Grammar Awareness course develop their sensitivity to language the workshop tasks were based on authentic texts - which tend to be linguistically richer and more unpredictable than text book texts. In addition to declarative knowledge, teachers need sensitivity to deal with such texts. They will come across language use which grammar rules either misrepresent or cannot cover. Citing Dansereau (1987), Blyth (1997, p.54) warns that "'leaky rules' are a common problem in grammatical analysis, especially in pedagogical grammars, which are ill-suited to capturing the variability inherent in language performance ".

The texts were chosen to exemplify specific linguistic features, and also to involve the learners affectively. They represented a range of cultural and geographical settings, and human predicaments (Appendix B) and ranged in length from half a page of A4 to 5 pages. The approach fell into quadrant 2 of Paran's (2008, p.467) characterization of 'the intersection of literature and language teaching', i.e. focus on language learning (in this case, learning about language) without literary focus. It was hoped that the students would be able to make enough links with other texts or with their own knowledge, experiences and interests to make the grammatical choices in the texts more meaningful. In learner terms, all of the texts and the tasks that went with them could be characterized as 'advanced'.

The workshop format addressed three more of Kumaravadivelu's (1994) strategies: (1) maximize learning opportunities; (2) facilitate negotiated interaction; (6) promote learner autonomy. The intention was that by talking about language with each other, learning opportunities would be maximized and that participants would learn by scaffolding and negotiating in mixed ability groups. The students' investigator role together with the absence of an answer key was meant to foster autonomy. The Grammar Awareness course thus sought to foster engagement with language through a course design which was essentially constructivist (Blyth, 1997), and based on socio-cultural principles (Lantolf \& Beckett, 2009; Vygotsky, 1978) and which sought to set up a mediation - internalization cycle of engagement with language leading to enhanced LA which could be drawn on in further engagement, and so on. 
The workshop tasks typically asked the students to identify particular linguistic features in the text. For example:

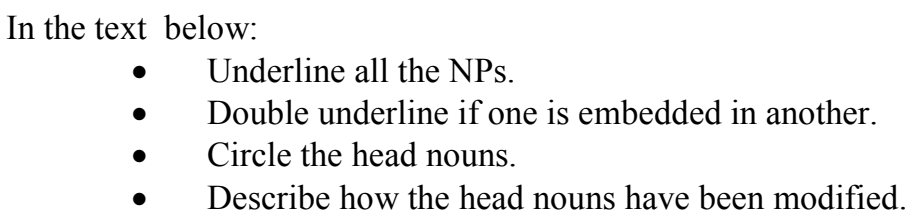

They would be asked to analyze and discuss. Some questions focused on meaning in context. In one text containing dialogue with modal verbs, the students were asked to specify the time reference of each modal, and then explain its function (e.g. to express willingness) and why the writer had chosen a particular form (with reference to social distance, intimacy and other interpersonal aspects). The tasks would often encourage the students to consider classroom implications.

While each of the pre-session activities had a key, the workshop tasks did not. This was meant to create 'cognitive conflict' (Tocalli-Beller, 2003; Tocalli-Beller \& Swain, 2005) and provide a genuine need for group discussion to negotiate solutions to the task. Dillenbourg et al (1996, p.4), discussing dyads, characterize "socio-cognitive conflict" from a Piagetian perspective as "conflict between different answers based on different centrations, embodied socially in the differing perspectives of the two subjects", and point out that such conflicts require some heterogeneity in the group. In the present study, there was a mix of experienced and novice teachers, and a wide range of abilities (as discussed above). There was no attempt to control for these variables in the workshop groupings.

It was expected that cognitive conflict would stimulate task focused negotiation and that for some this might result in anxiety, but it was also hoped that the emerging knowledge would be more in-depth than if 'correct answers' had been provided by the tutor. Making the groups rely on their own negotiated solutions had the potential to foster autonomy and provide training in some of the analytical skills language teachers need in order to evaluate and choose appropriate texts, understand and help their learners overcome grammar errors and so on.

The above description of the workshops applied to both cohorts. In $\mathrm{C} 1$, the students had been free to form groups and conduct the group work in whatever way they saw fit. In 200910 the format was changed as the feedback from $\mathrm{C} 1$ indicated some problems, especially with task focus and participation. 
Workshops in C2 were more structured and had what I will call a 'cooperative' format (Oxford 1997). A cooperative feature was the assignment of roles within the group (see below), but other characteristics of cooperative learning were not specifically promoted (see DelliCarpini 2009, p.43-4, citing Johnson \& Johnson 1999), e.g. solutions were not handed in or checked by the tutor so members were not accountable other than to the group. In this respect the format might be called merely 'collaborative' (Oxford 1997; Dillenbourg et al 1996, p.2). The group size was limited to between 5 and 7, and mono-lingual groups were not allowed. Each group had a 'facilitator', a 'time keeper' and a 'scribe'. The facilitator's function was to encourage passive or shy people to participate, and to prevent others from dominating. The time keeper helped the group to get through the task in the time available. The scribe would write down any questions the group wished to put to the tutor, who would deal with them in the following lecture or by email circulation. In practice, the two former roles proved essential but the scribe was rarely made use of.

As the present study did not include observation, peer tutoring will not be referred to below but student interviews made it clear that it was an integral part of the workshop interaction. There has been a great deal of research on peer tutoring and the learning resulting from it, mainly in school contexts. Both stronger and weaker students can benefit. As Barron (2003, p.308) points out, collaborative learning can offer a range of learning opportunities; participants have to put forward arguments and explain their own views, perhaps resolve differences of opinion, and observe others doing the same. It has been shown that learning can result not only from being the recipient of peer tutoring but, crucially, from tutoring itself (Roscoe \& Chi, 2007), and De Guerrero and Villamil (2000) found scaffolding between more or less skilled learners in a writing class to be mutual rather than unidirectional.

\section{The Survey}

The general question of the study was to what extent the Grammar Awareness pedagogy was successful or not in fostering engagement with language. Three sub-questions are relevant to the present paper:

1. Were the workshops conducive to Engagement?

2. Did background affect Engagement in the workshops, and if so how?

3. Did changes to the course design affect Engagement in the workshops, and if so how?

The survey results were compared, as indicated by questions 2 and 3, and shown in Fig.1 below. 
Qu.2

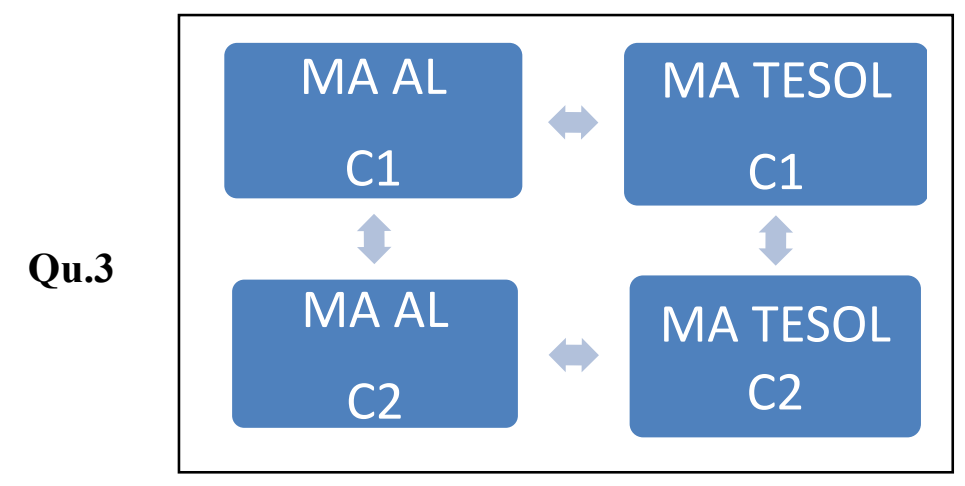

Figure 1. Comparison of student groups according to background and cohort

In the figure above, the double-headed arrows show which data sets were compared. Research question 2 was answered by comparing the MA AL with the MA TESOL stream, i.e. experienced versus novice teachers. Answers to question 3 were sought through a comparison of the 2008-9 cohort (C1) with the 2009-10 cohort (C2).

The survey instrument contained Likert scale items and space for optional, open ended comments. In all, 78 of 98 questionnaires were returned, 31/44 from $\mathrm{C} 1$ and 47/52 from C2 (Table 2 above). The questions required a degree of agreement or disagreement on a fivepoint scale and, following a short background information section on the students' perceptions of themselves, were related to the different components of the course design:

- Self-Perception

- The lectures

- The worksheets

- The pre-session activities

- The texts and workshops

- The course as a whole

The questions dealt with general satisfaction with the course, and then factors which might facilitate or obstruct engagement with language, e.g. focused attention and willingness or ability to participate. The texts and workshops and course-as-a-whole sections are discussed below, making reference to students' self-perceptions as appropriate.

The questionnaire was anonymous and was distributed after the completion of the course, at the end of a question/answer session. The students were given the option of completing it in class and handing it to a student representative, or taking it away and returning it later. Most chose to complete it immediately. The questionnaire included information about its purpose and the option to allow or disallow its use in research. All who returned the questionnaire indicated that it could be used for research. 


\section{Findings}

To make groups more easily comparable, and given the small number of participants in each strand and cohort, the number of responses was converted into percentages without any further statistical processing. The approach taken instead was to look for 'patterns', for example differences or shifts in responses on questions of a similar nature pointing in the same direction. For the purpose of analysis the questions were grouped according to five themes: General Satisfaction with the course, Difficulty \& Cognitive Conflict, Autonomy, Noticing \& Concentration, and Participation, and patterns identified within the themes (Appendix C).

The outcome of the $\mathrm{C} 1$ survey will first be summarized very briefly and schematically with emphasis on the main issues which emerged from it. The data for both cohorts will subsequently be presented, compared and discussed in more detail. The following abbreviations are used: SA (Strongly Agree), A (Agree), NAD (Neither Agree nor Disagree), D (Disagree), SD (Strongly Disagree). In the interest of conciseness, MA AL and MA TESOL will be referred to below as AL and TESOL.

\section{The Workshop Element of the Course According to the First Cohort of Students}

Overall, the C1 students' satisfaction with the course was high, in terms of how much they felt they had learnt, and how useful or interesting it had been. The overwhelming majority in both groups either strongly agreed or agreed that the workshops had been useful (qu.12, SA/A: AL 83\%; TESOL 100\%), and none disagreed. Nearly three quarters in both strands rejected the proposition that they had not learnt a lot (qu.28, D/SD: 71\%). Although these subjective perceptions of learning were not necessarily accurate, they were relevant as they were likely to have affected the students' engagement with language.

A number of questions (qu.6, 13, 22, 24) explored the students' attitudes to and experience of task difficulty. There were some major differences between the groups. Only $17 \%$ of the AL students felt tasks had been too difficult, as against nearly all of the TESOL students (SA/A: 93\%). One might expect the TESOL students to also find the texts on which the tasks were based more difficult than their experienced peers but this was not the case; $24 \%$ of the AL students in $\mathrm{C} 1$ found the texts too difficult, as against only $14 \%$ of the TESOL students. Though the difference was small, one interpretation is that some novice teachers were satisfied with a surface understanding of the texts and had not engaged with them in sufficient depth to become aware of the difficulties. A majority in both groups had apparently 
found the lack of an answer key stressful (qu.24 "Not having an answer key to some of the activities and exercises made me anxious"; SA/A AL 82\%; TESOL 64\%). It was particularly interesting that more AL than TESOL students had felt this way.

Focused attention was an issue in both groups (qu.14: "During group work, I found it easy to concentrate."), but more so for the novice teachers: over $40 \%$ had problems concentrating during the workshops and none had found it easy, as against the $44 \%$ of the AL group who indicated that concentration was not a problem.

Five questions addressed the students' readiness to participate, their actual participation and their perceptions of its contribution (or not) to their learning. Major differences between the groups emerged. Nearly $20 \%$ more TESOL than AL students rejected the characterization of themselves as 'outgoing and sociable' (qu.3 "I would describe myself as an outgoing and sociable person"); $57 \%$ of the TESOL students preferred to listen (qu.7 "During group work, I prefer to listen to others."), as against $28 \%$ in the AL group, and only one TESOL student, as against $83 \%$ of the AL students, rejected the notion that they had not been very active (qu.15 "I didn't participate much in the group work."). Despite this, more TESOL than AL students felt they had 'learnt a lot', either by discussing with other students (qu.25 "I learnt a lot on this course by discussing with other students", SA/A: AL 53\% - TESOL 71\%) or by individual study (qu.27. "I learnt a lot on this course by studying on my own", SA/A: AL $29 \%$ - TESOL $54 \%$ ).

The $\mathrm{C} 1$ survey thus raised some concerns. One was the proportion of students in both groups who did not think, or were not sure, that they had 'learnt a lot'. Also, the two groups did not seem to benefit equally: the TESOL students found focusing on the task and active participation particularly difficult. Anxiety was unexpectedly high, and higher amongst the experienced teachers.

\section{The First and Second Cohorts' Views of the Workshops Compared}

Following analysis of the $\mathrm{C} 1$ survey data (plus interviews not discussed in this paper) changes were made to the workshop format to make it more structured and cooperative, as described above, but the tasks remained the same. The same survey instrument was then administered to $\mathrm{C} 2$. The responses of the two cohorts will be compared below. In order to make the tables more easily readable, the Likert scale has been telescoped from five to three steps: SA/A, NAD, D/SD. Due to rounding up, the figures do not always add up to exactly $100 \%$.

The items dealing with general satisfaction with the course are shown in Table 4: 
Table 4. C1 \& C2 Compared: General Satisfaction (in percentages)

\begin{tabular}{|c|c|c|c|c|c|c|c|}
\hline \multirow[b]{2}{*}{ Item } & \multirow[b]{2}{*}{ Stream } & \multicolumn{3}{|c|}{ C1 (2008-9) } & \multicolumn{3}{|c|}{ C2 (2009-10) } \\
\hline & & SA/A & NAD & D/SD & SA/A & NAD & D/SD \\
\hline \multirow{2}{*}{$\begin{array}{l}\text { 12. The workshop activities were useful } \\
\text { to me. }\end{array}$} & $\mathrm{AL}$ & 83 & 17 & 0 & 88 & 0 & 12 \\
\hline & TESOL & 100 & 0 & 0 & 70 & 20 & 10 \\
\hline \multirow{2}{*}{$\begin{array}{l}\text { 21. The texts made the course more } \\
\text { interesting. }\end{array}$} & $\mathrm{AL}$ & 47 & 41 & 12 & 88 & 12 & 0 \\
\hline & TESOL & 79 & 21 & 0 & 67 & 23 & 10 \\
\hline \multirow{2}{*}{$\begin{array}{l}\text { 23. Seeing the grammar in context was } \\
\text { useful. }\end{array}$} & $\mathrm{AL}$ & 100 & 0 & 0 & 94 & 6 & 0 \\
\hline & TESOL & 100 & 0 & 0 & 93 & 7 & 0 \\
\hline \multirow[t]{2}{*}{ 26. I did not learn a lot on this course. } & $\mathrm{AL}$ & 6 & 24 & 71 & 0 & 18 & 82 \\
\hline & TESOL & 0 & 29 & 71 & 7 & 27 & 67 \\
\hline \multirow{2}{*}{$\begin{array}{l}\text { 28. What I learnt on this course will be } \\
\text { useful to me as a teacher. }\end{array}$} & $\mathrm{AL}$ & 82 & 18 & 0 & 82 & 12 & 6 \\
\hline & TESOL & 100 & 0 & 0 & 90 & 7 & 3 \\
\hline \multirow{2}{*}{$\begin{array}{l}\text { 29. I am more interested in Grammar } \\
\text { now than before the course. }\end{array}$} & $\mathrm{AL}$ & 41 & 53 & 6 & 65 & 24 & 6 \\
\hline & TESOL $^{*}$ & 57 & 43 & 0 & 63 & 33 & 3 \\
\hline
\end{tabular}

$\mathrm{SA}=$ Strongly Agree; $\mathrm{A}=$ Agree; NAD = Neither Agree nor Disagree; $\mathrm{D}=$ Disagree; $\mathrm{SD}=\mathrm{Strongly}$ Disagree

AL C1 \& $\mathrm{C} 2$ : $\mathrm{N}=17$ (1 student $=6 \%$ ); TESOL: $\mathrm{C} 1 \mathrm{~N}=14$ (1 student=7\%); $\mathrm{C} 2 \mathrm{~N}=30$ (1 student=3\%)

*One missing answer

After the introduction of a cooperative format, the level of satisfaction remained high, as indicated by the $\mathrm{D} / \mathrm{SD}$ replies to qu.26 and the SA/A responses to qu.12, 21, 23 and 28, but there were some interesting differences between the cohorts and between the strands. Regarding the usefulness of the workshops (qu.12), there was a slight negative shift. In $\mathrm{C} 2$, two AL students and three TESOL students did not find them useful, as against none in $\mathrm{C} 1$. The majority view was, however, still that the workshops had been useful and more AL students (SA/A: 88\%) than TESOL students (SA/A: 70\%) shared this perception. Nearly all the students in both strands still appreciated the contextualization of the grammar (qu.23).

The proportion of AL students who found the texts interesting (qu.21) increased markedly from $47 \%$ to $88 \% \mathrm{SA} / \mathrm{A}$. Again there was a slight negative shift in the TESOL group. The difference between the TESOL and AL students was apparent also in qu.26. In C1, around $71 \%$ in each strand rejected the proposition that they had not learnt a lot, while in C2 a slight shift in both groups but in opposite directions created a $15 \%$ gap, with more of the experienced teachers feeling they had benefitted. A large majority in C2 still thought that what they had learnt would be useful to them as teachers (qu.28). Interestingly, there was a slight positive shift on qu.29, with more students choosing to agree with the suggestion that the course had increased their interest in grammar. The gain was greater in the AL group (nearly 24\%), consistent with the overall impression that they had benefitted more.

Differences between the cohorts were slight on all the general satisfaction questions bar one, but all pointed towards the same conclusion, that the novice teachers in C2 had struggled more with the workshops than their counterparts in $\mathrm{C} 1$. For the experienced teachers, in contrast, the cooperative workshops appear to have generated more interest and possibly 
more learning. Since the numbers are small, these tentative conclusions will be tested against student replies to the more specific questions below.

On qu.4 and qu.6, which explored learning preferences related to autonomy, it was assumed that to some extent the students' recent experiences in the workshops would be reflected in the replies. The magnitude of the shifts shown in Table 5 below makes it likely that this was the case.

Table 5. C1 \& C2 Compared: Autonomy (in percentages)

\begin{tabular}{|c|c|c|c|c|c|c|c|}
\hline & & \multicolumn{3}{|c|}{ C1 (2008-9) } & \multicolumn{3}{|c|}{ C2 (2009-10) } \\
\hline \multicolumn{2}{|l|}{ Item } & SA/A & NAD & D/SD & SA/A & NAD & D/SD \\
\hline \multirow[t]{2}{*}{ 4. I like working things out for myself. } & $\mathrm{AL}$ & 83 & 11 & 6 & 53 & 35 & 12 \\
\hline & TESOL & 79 & 21 & 0 & 60 & 33 & 7 \\
\hline \multirow{2}{*}{$\begin{array}{l}\text { 6. I like difficult tasks; they can be an } \\
\text { interesting challenge. }\end{array}$} & $\mathrm{AL}^{*}$ & 39 & 44 & 11 & 71 & 24 & 6 \\
\hline & TESOL * & 43 & 57 & 0 & 40 & 47 & 10 \\
\hline
\end{tabular}

$\mathrm{SA}=$ Strongly Agree; $\mathrm{A}=$ Agree; $\mathrm{NAD}=$ Neither Agree nor Disagree; $\mathrm{D}=$ Disagree; $\mathrm{SD}=$ Strongly Disagree

AL C1 \& C2: N=17 (1 student=6\%); TESOL: C1 N=14 (1 student=7\%); C2 N=30 (1 student=3\%)

*One missing answer

The C2 students, who had experienced the cooperative workshops, were less adamant that they liked working things out for themselves (qu.4). 30\% more students in the AL group and $18 \%$ more in TESOL were non-committal or disagreed (D/SD) with this item. Unfortunately, however, the question was ambiguous. A negative response can either be interpreted as a greater appreciation of the power of co-construction of knowledge, or as a lack of autonomy (a greater need for answer keys, for example). On qu.6, a markedly larger proportion of $\mathrm{AL}$ students in $\mathrm{C} 2$ than in $\mathrm{C} 1$ appreciated the challenge of a difficult task (a 32\% gain) while there was a slight negative shift in the TESOL group. This resulted in a 31\% gap opening up between students in the two strands who agreed (SA/A) on this question. Looking at the two items together, it is possible that the differences reflect that the stronger students had benefitted from working collaboratively, while for some of the weaker students collaboration was a cause of added insecurity.

The impression that the cooperative format had disadvantaged the TESOL students was, however, somewhat modified by their perceptions of task difficulty (qu.13, Table 6 below).

Table 6. C1 \& C2 compared: Difficulty \& Cognitive Conflict (in percentages)

\begin{tabular}{|c|c|c|c|c|c|c|c|}
\hline \multirow[b]{2}{*}{ Item } & \multirow[b]{2}{*}{ Stream } & \multicolumn{3}{|c|}{ C1 (2008-9) } & \multicolumn{3}{|c|}{ C2 (2009-10) } \\
\hline & & SA/A & NAD & D/SD & SA/A & NAD & D/SD \\
\hline \multirow{2}{*}{$\begin{array}{l}\text { 13. The workshop activities were too } \\
\text { difficult. }\end{array}$} & $\mathrm{AL}$ & 17 & 39 & 44 & 6 & 47 & 47 \\
\hline & TESOL & 93 & 7 & 0 & 27 & 43 & 30 \\
\hline \multirow[t]{2}{*}{ 22. The texts were too difficult. } & $\mathrm{AL}$ & 24 & 29 & 47 & 12 & 41 & 47 \\
\hline & TESOL & 14 & 57 & 29 & 23 & 57 & 20 \\
\hline \multirow{2}{*}{$\begin{array}{l}\text { 24. Not having an answer key to some } \\
\text { of the activities and exercises made me }\end{array}$} & $\mathrm{AL}$ & 82 & 12 & 6 & 82 & 6 & 12 \\
\hline & TESOL & 64 & 36 & 0 & 87 & 3 & 10 \\
\hline
\end{tabular}


anxious.

$\mathrm{SA}=$ Strongly Agree; $\mathrm{A}=$ Agree; $\mathrm{NAD}=$ Neither Agree nor Disagree; $\mathrm{D}=$ Disagree; $\mathrm{SD}=$ Strongly Disagree

AL C1 \& C2: $\mathrm{N}=17$ ( 1 student= 6\%); TESOL: $\mathrm{C} 1 \mathrm{~N}=14$ (1 student=7\%); $\mathrm{C} 2 \mathrm{~N}=30$ (1 student=3\%)

In $\mathrm{C} 1$, nearly $93 \%$ of the TESOL students agreed (SA/A) that the tasks were too difficult. In $\mathrm{C} 2$, this was reduced to $27 \%$. There was a similar but much smaller shift in the AL group from $17 \%$ to $6 \%$. It would seem that the cooperative format had ameliorated task difficulty, in particular for the TESOL students.

The same was not true for text difficulty. In C2, slightly more TESOL students felt the texts were too difficult, while a few more AL students chose not to commit themselves. In addition, the novice teachers' level of anxiety had increased (qu.24); in both groups, over $80 \%$ now found the lack of an answer key stressful; the TESOL students' SA/A replies to this question increased by $22 \%$. It is interesting in this context to note that very few workshop groups made use of the option to put questions to the tutor through the scribe.

Nevertheless, in addition to ameliorating task difficulty, the cooperative format appears to have had a major positive effect on the TESOL students' ability to focus on the task, as shown in Table 7 below.

Table 7. C1 \& C2 Compared: Noticing \& Concentration (in percentages)

\begin{tabular}{|c|c|c|c|c|c|c|c|}
\hline \multirow[b]{2}{*}{ Item } & \multirow[b]{2}{*}{ Stream } & \multicolumn{3}{|c|}{ C1 (2008-9) } & \multicolumn{3}{|c|}{ C2 (2009-10) } \\
\hline & & SA/A & NAD & D/SD & $\mathbf{S A} / \mathbf{A}$ & NAD & D/SD \\
\hline 1. I have often noticed and thought & $\mathrm{AL}$ & 100 & 0 & 0 & 88 & 6 & 6 \\
\hline about how people use language. & TESOL & 79 & 21 & 0 & 80 & 17 & 3 \\
\hline 14. During group work, I found it easy & $\mathrm{AL}$ & 44 & 39 & 17 & 65 & 24 & 12 \\
\hline to concentrate. & TESOL* & 0 & 57 & 43 & 47 & 30 & 20 \\
\hline
\end{tabular}

$\mathrm{SA}=$ Strongly Agree; $\mathrm{A}=\mathrm{Agree} ; \mathrm{NAD}=$ Neither Agree nor Disagree; $\mathrm{D}=$ Disagree; $\mathrm{SD}=$ Strongly Disagree AL C1 \& C2: $\mathrm{N}=17$ ( 1 student= 6\%); TESOL: $\mathrm{C} 1 \mathrm{~N}=14$ (1 student=7\%); $\mathrm{C} 2 \mathrm{~N}=30$ (1 student=3\%)

*One missing answer

The two strands differed markedly in their ability to concentrate on the task (qu.14); AL students found it easier than TESOL students. The more structured C2 workshop format, however, improved concentration for the TESOL students in particular. Their SA/A responses to this question rose from $0 \%$ to $47 \%$, while there was a smaller, $20 \%$ gain in the AL group's agreement score. The gap between the AL and TESOL students in this respect shrunk from $44 \%$ to around $18 \%$.

In response to qu.1, a minority of novice teachers (3 in $\mathrm{C} 1$ and 6 in $\mathrm{C} 2$ ) and one experienced teacher (in C2) were not sure whether they often paid attention to language use, but the overwhelming majority of students in both cohorts and strands declared that they did. 
The items addressing the students' participation (Table 8 below) revealed some interesting shifts in perception. There was no longer a gap in their characterization of themselves as 'outgoing and sociable' (qu.3); the two C2 groups were indistinguishable in this respect.

Table 8. C1 \& C2 Compared: Participation (in percentages)

\begin{tabular}{|c|c|c|c|c|c|c|c|}
\hline \multirow[b]{2}{*}{ Item } & & \multicolumn{3}{|c|}{ C1 (2008-9) } & \multicolumn{3}{|c|}{ C2 (2009-10) } \\
\hline & & SA/A & NAD & D/SD & SA/A & NAD & D/SD \\
\hline 3. I would describe myself as an & $\mathrm{AL}$ & 50 & 33 & 17 & 59 & 35 & 6 \\
\hline outgoing and sociable person. & TESOL & 42 & 21 & 36 & 57 & 36 & 7 \\
\hline 7. During group work, I prefer to listen & $\mathrm{AL}$ & 28 & 28 & 44 & 24 & 47 & 29 \\
\hline to others. & TESOL & 57 & 36 & 7 & 10 & 53 & 37 \\
\hline 15. I didn't participate much in the & $\mathrm{AL}$ & 0 & 17 & 83 & 6 & 12 & 82 \\
\hline group work. & TESOL* & 29 & 64 & 7 & 0 & 10 & 87 \\
\hline 25. I learnt a lot on this course by & $\mathrm{AL}$ & 53 & 35 & 12 & 88 & 6 & 6 \\
\hline discussing with other students. & TESOL & 71 & 29 & 0 & 73 & 17 & 10 \\
\hline 27. I learnt a lot on this course by & $\mathrm{AL}$ & 30 & 53 & 18 & 71 & 24 & 6 \\
\hline studying on my own. & TESOL & 64 & 36 & 0 & 60 & 30 & 10 \\
\hline
\end{tabular}

$\mathrm{SA}=$ Strongly Agree; $\mathrm{A}=$ Agree; $\mathrm{NAD}=$ Neither Agree nor Disagree; $\mathrm{D}=$ Disagree; $\mathrm{SD}=$ Strongly Disagree AL C1 \& $\mathrm{C} 2$ : $\mathrm{N}=17$ ( 1 student $=6 \%$ ); TESOL: $\mathrm{C} 1 \mathrm{~N}=14$ (1 student=7\%); $\mathrm{C} 2 \mathrm{~N}=30$ (1 student $=3 \%$ )

*One missing answer

In $\mathrm{C}$, there had also been a clear difference between the two groups on qu.7, indicating that the novice teachers tended to prefer listening to others during group work, while the experienced teachers showed a strong tendency in the opposite direction. In $\mathrm{C} 2$, the groups had become more similar. Fewer AL students dispreferred listening, and fewer TESOL students preferred it. As a result, about half of each group neither agreed nor disagreed on this item (NAD: AL 47\%; TESOL 53\%). One interpretation is that through the cooperative format, and in particular the actions of the facilitator, the experienced teachers had come to appreciate the value of listening while the novice teachers had been enabled to contribute more actively to the conversations. The latter is supported to some extent by a major shift on qu.15: after the changes to the workshop format, $80 \%$ more TESOL students denied that their participation rate had been low. This resulted in the two groups being very similar in this respect (D/SD: AL 82\%; TESOL 87\%), reducing the gap between the groups from $76 \%$ to $4 \%$.

There were interesting differences between the cohorts regarding the mode of learning (qu.25 \& qu.27). In C1, the TESOL students had been more adamant than the AL group that they had learnt a lot both by peer interaction, and by studying on their own. In C2, these perceptions had shifted, so that the number of AL students who agreed on the benefit of peer discussion (qu.25) had increased by 35\% (SA/A: 88\%), and those who felt they had learnt a lot by independent study (qu.27) had increased by $42 \%$ (SA/A: $71 \%$ ). In contrast, the TESOL students' perceptions were virtually unchanged, around 60\% SA/A. 


\section{Discussion}

This study did not attempt to determine the effect of the pedagogy on final outcomes. The issue it addressed was what effect changes to the workshop format would have on factors likely to facilitate or hinder the students' engagement with language, and whether experienced and novice teachers' perceptions differed. I would argue that when tendencies in the data are considered by theme a strong narrative emerges.

When the AL and TESOL students were compared (research question 2), the strong impression in both $\mathrm{C} 1$ and $\mathrm{C} 2$ was that the latter were the less confident. The novice teachers in C2 were less keen on 'difficult tasks' and more novice than experienced teachers found the tasks and the texts 'too difficult'. Despite a marked improvement, the C2 TESOL students still found concentrating on the task harder than the AL students. None of this was surprising, but served to underline that the course caters for students with different backgrounds and needs.

To answer also the third research question, whether the introduction of the cooperative workshop format had made a difference, student responses in $\mathrm{C} 1$ were compared to those in C2. The main tendencies are summarized below. As Table 9 shows, different narratives emerge for the experienced and the novice teachers.

There were several indications that the AL students had benefitted from the cooperative workshop format. Compared to $\mathrm{C} 1$, the $\mathrm{C} 2 \mathrm{AL}$ students were more positive towards 'challenging tasks' and found the texts on which the tasks were based more interesting. Their interest in grammar had also increased more. They had an enhanced sense of having 'learnt a lot', whether by peer interaction or, interestingly, by independent study. They found concentrating on the task easier. They had been very active participants already in $\mathrm{C} 1$, but took on more of a listening role in $\mathrm{C} 2$. They also showed less of an inclination towards 'working things out for themselves' which, in this context, might mean a greater appreciation of peer interaction. It could, however, also mean that the need for an answer key had been enhanced - like their TESOL peers, most AL students felt anxious about not having the correct answers to the tasks.

Table 9. Differences in the C2 AL and TESOL Students' Perceptions Compared to those of C1

\begin{tabular}{lll}
\hline AL & TESOL \\
\hline$\circ$ & greater interest in the texts & $\circ \quad 30 \%$ fewer found the workshops \\
$\circ$ & greater sense of having learnt a lot & 'useful' \\
\hline
\end{tabular}




\begin{tabular}{|c|c|}
\hline $\begin{array}{l}0 \text { a greater gain in grammar interest } \\
0 \text { more positive towards 'challenging } \\
\text { tasks' } \\
0 \text { focusing on the task was facilitated } \\
0 \text { taking more of a listening role } \\
0 \text { greater appreciation of learning by } \\
\text { peer discussion } \\
0 \text { more positive about learning } \\
\text { independently } \\
0 \text { preference for 'working things out by } \\
\text { [themselves]' decreased } \\
0 \text { high anxiety about lack of key } \\
\text { maintained }\end{array}$ & $\begin{array}{l}\circ \text { the tasks appeared less difficult } \\
\circ \text { but text difficulty was not reduced } \\
\circ \text { focusing on the task was facilitated } \\
\circ \text { more active participation } \\
\circ \text { preference for 'working things out by } \\
\text { [themselves]' decreased } \\
\circ \text { markedly more anxious about lack of } \\
\text { key }\end{array}$ \\
\hline
\end{tabular}

The TESOL students, who lacked the professional experience of the AL group, gave the general impression of finding the workshops very challenging in both $\mathrm{C} 1$ and $\mathrm{C} 2$. The cooperative format, however, appears to have facilitated their engagement in important respects. Indications of this were that compared to $\mathrm{C} 1$, the $\mathrm{C} 2$ TESOL students participated more actively in the workshops, taking less of a listening role, and found the tasks less difficult. Nearly half (as compared to none in $\mathrm{C} 1$ ) found it easy to focus on the task in the cooperative workshops.

Ability to focus and perception of task difficulty may be linked. In C1, the novice teachers not only had greater problems concentrating on the task than the AL students, but also found the group tasks more difficult (Table 6, qu.13). The direction of causality is not possible to establish but it seems reasonable to assume both that the high task demands contributed to lack of concentration, and that other factors, for example to do with group dynamics, might have distracted the students' attention thereby contributing to making the tasks harder to solve. Changes to the group dynamics caused by the cooperative format may have lead to fewer distractions thereby facilitating engagement with the task.

The Facilitator's role in particular had the potential to create a better balanced pattern of participation, and that appears to have happened, with TESOL students becoming more active and AL students more ready to listen. The importance of the listening role in collaborative work is pointed out by Barron (2003, p.310), who sees the management of attention as essential for successful outcomes: "both speakers and listeners have consequential roles to play in establishing joint attention."

The following interview excerpt with an AL C2 student indicates that some groups were successful:

sometimes we get stuck with something and when we talk about it everybody give you ideas that you know trigger your ideas and - you understand more and get the inspiration of what is in it 
But there were others who were not, as in this comment from a C2 TESOL student on the survey paper:

Some students were passive during the group work - they expected everything to be told by others. As this implies, there was no discussion/ agreement/ disagreement about the activities and as a result group work was not at all beneficial for us.

Regarding passivity, Dillenbourg et al (1996, p.8) comment "some negative effects [of collaborative learning] are stable and well documented, for instance the fact that low achievers progressively become passive when collaborating with high achievers (Salomon and Globerson,1989; Mulryan, 1992)." The survey data cannot reveal whether the mix of strong and weak students was a serious problem. The students varied in a number of ways other than ability, including age, L1 and cultural background. Barron (2003, p.310) emphasizes the importance of the quality of interaction and suggests that collaborative group work creates a dual-problem space involving both a content-space and a relational-space, where both content and interpersonal issues compete for limited attention.

For whatever reason, there were strong indications that the cooperative format had exacerbated the challenges for the weaker students. Despite over $70 \%$ of the TESOL students (in $\mathrm{C} 1$ and $\mathrm{C} 2$ ) declaring that they had 'learnt a lot' by discussing with their peers, in C2 30\% fewer TESOL students agreed that the workshops had been useful to them. Three factors might have combined to create this perception: the pressure on each student in the cooperative groups to formulate their views; the fact that shared knowledge could not be relied on in the multi-lingual, multi-cultural groups and the consequent need for more explicit and precise formulations; the absence of keys to the workshop tasks. Despite the tasks being perceived as easier (see above) the cooperative format made both groups, and the TESOL students in particular, feel more anxious about the lack of keys.

The fact that the high level of anxiety did not result in overall negative perceptions of the course, however, made me question my interpretation. Researchers such as Ariza (2002), Brown (2008), Ewald (2007), and contributors to Horwitz \& Young's (1991) edited volume on the topic, consider anxiety in language learning as negative and something which needs to be relieved and minimized. Ohata (2005), in contrast, explored also the positive aspects of anxiety. A radically different approach was adopted by Spielmann \& Radnofsky (2001) in an ethnographic study of learners on a residential immersion French Language course. Realizing that 'anxiety' did not adequately describe the range of phenomena their respondents described, they opted for the wider term 'tension'. Tension can be positive or negative, or neutral. Anxiety is a negative type of tension ('affective dysphoria', p.259). A neutral type of 
tension is what has been called 'flow' (p.262, citing Csikszentmihalyi 2000), a state of optimal focusing where creativity and learning can appear effortless. In hindsight, the explicit mention of anxiety introduced a bias and so, having deliberately set about creating 'cognitive conflict' through challenging tasks, a very high agreement with the question about anxiety ought to have been predicted. Among those who agreed could be students who felt anything from panic to a sense of 'cognitive euphoria' (Spielmann \& Radnofsky, fig.1, p.263). In other words, it is not possible to tell whether what they were inadvertently prompted to classify as anxiety was a problem or in fact had facilitated their learning.

\section{Conclusion and Implications}

Some of the issues identified in C1 appear to have been addressed very successfully by the cooperative format applied in $\mathrm{C} 2$, which consisted of role assignment plus a ban on monolingual groups. The AL students' perception of having 'learnt a lot', by whatever mode, increased; the TESOL students participated more actively; and focusing on the task was facilitated for both groups. In addition, the tasks, which had been too difficult for nearly all the novice teachers, were perceived as much less difficult in the cooperative workshops. While the novice teachers still appeared to find the workshops more difficult than their experienced colleagues, the two groups' perceptions had become more similar. This perceptual 'closing of the gap' cannot be explained by the $\mathrm{C} 2$ groups being more similar than $\mathrm{C} 1$ as the average final test scores indicate quite the opposite (Appendix A).

A possible interpretation is as follows. Focused attention and participation - key components of engagement with language - both improved, along with level of interest (in the texts, in grammar, in challenging tasks). At the same time, the cooperative format was likely to create an enhanced sense of learning for the stronger students while for the weaker students it might highlight lack of, or gaps in, knowledge. The cooperative framework forces passive (or quiet) students to become more (overtly) active, and encourages a greater depth of engagement. For stronger students, that could make texts and tasks more interesting and satisfying; for weaker or less confident students it could simply emphasize what they do not know.

One concern which remains to be addressed is anxiety. Although the data was difficult to interpret, it is quite possible that anxiety hampered learning for some students. The solution might seem simple: provide task keys. This could, however, remove the impetus for in-depth negotiation. Dillenbourg et al. (1996, p.14), discussing computer based tasks, and citing Fraisse's (1987) study on children, state: “it seems that immediate feedback may prevent 
fruitful exchanges between human co-learners because they then rely on the system to test their hypotheses instead of developing arguments to convince one another." Even in a different, non-computer based context, the availability of a key could for many students eliminate the reason for group discussion.

Nevertheless, to be a positive driving force anxiety/tension needs to be controlled. One possibility is to provide a suggested solution on the first couple of lines (or other small portion) of the text 15 minutes into the workshop. The students then continue with the rest of the task as before. The role of the 'scribe' can also be strengthened by requiring each group to submit one question to the course tutor after each workshop session. It would normally be dealt with at the beginning of the next lecture or by answers posted in the VLE. These measures need to be evaluated, but have the potential to alleviate some of the anxiety without removing the reason for engaging in depth with the language in the cooperative workshops.

Findings from this kind of practice driven, small scale study cannot easily be generalized, but a fairly detailed account of the context and pedagogy has been provided for other practitioners/researchers in analogous situations who might be interested in testing the conclusions reached here in further research.

\section{Acknowledgements}

I would like to thank the anonymous reviewers for very helpful comments. The completion of this study and paper was made possible by a period of research leave granted by the University of Leicester. The author is grateful in particular for the support of colleagues in the School of Education.

\section{Notes}

1. "Language Awareness can be defined as explicit knowledge about language, and conscious perception and sensitivity in language learning, language teaching and language use." http://www.lexically.net/ala/la defined.htm (13 October, 2010)

2. It was not possible to include a quantitative measure of knowledge at entry, or of outcomes, one reason being the difficulty of measuring grammar awareness holistically, i.e in the way it was taught. The author hopes to address this issue in a separate research project.

3. Greenbaum \& Nelson (2002). During the first cohort there were no keys to the exercises in the set text. By the second cohort, the publishers were providing a key to the $3^{\text {rd }}$ edition on a dedicated website.

\section{Note on contributor}

\section{References}


Ariza. E. N. (2002). Resurrecting “Old” Language Learning Methods to Reduce Anxiety for New Language Learners: Community Language Learning to the Rescue. Bilingual Research Journal, 26: 3, pp.717 - 728.

Barron, B. (2003). When smart groups fail. The Journal of the Learning Sciences, 12(3), 307359.

Blyth, C. (1997). A constructivist approach to grammar: Teaching teachers to teach aspect. The Modern Language Journal, 81(1), 50-66.

Borg, S. (1994). Language awareness as a methodology: Implications for teachers and teacher training. Language Awareness, 3(2), 61-71.

Brown, L. (2008). Language and Anxiety: An Ethnographic Study of International Postgraduate Students. Evaluation \& Research in Education. 21(2), 75-95.

Csikszentmihalyi, M. (2000). Flow: The psychology of optimal experience. New York: Harper Row.

Dansereau, D. (1987). A discussion of techniques used in the teaching of the passe compose/imparfait distinction in French. The French Review, 61, 33- 38.

De Guerrero, M.C.M. \& Villamil, O.S. (2000). Activating the ZPD: Mutual scaffolding in L2 peer revision. The Modern Language Journal, 84(1), 51-68.

DelliCarpini, M. (2009). Enhancing cooperative learning in TESOL teacher education. ELT Journal, 63(1), 42-50.

Dillenbourg, P., Baker, M., Blaye, A. \& O'Malley, C. (1996). The evolution of research on collaborative learning. In E. Spada \& P. Reiman (Eds.) Learning in humans and machine: Towards an interdisciplinary learning science. (pp. 189-211). Oxford: Elsevier.

Ewald, J. D. (2007). Foreign Language Learning Anxiety in Upper-Level Classes: Involving Students as Researchers. Foreign Language Annals, 40(1), 122-142.

Fraisse, J. (1987). Etude du rôle perturbateur du partenaire dans la découverte d'une stratégie cognitive chez des enfants de 11 ans en situation d'interaction sociale. Bulletin de Psychologie, 382, 943-952.

Greenbaum, S. \& Nelson, G. (2002) An introduction to English grammar. London: Longman. Horwitz, E. K. \& Young, D. J. (Eds.). (1991). Language anxiety: From theory to research to classroom implications. Englewood Cliffs, NJ: Prentice Hall.

Halliday, M. A. K. (1985). An introduction to functional grammar. London: Edward Arnold. Johnson, D. W. and Johnson. R. T. (1999). Building community through cooperative learning. Theory into Practice, 38(2), 67-73. 
Kumaravadivelu, B. (1994). The postmethod condition: (E)merging strategies for second/foreign language teaching. TESOL Quarterly, 28, 27-48.

Kumaravadivelu, B. (2001). Toward a postmethod pedagogy. TESOL Quarterly, 35, 537560.

Kumaravadivelu, B. (2006). TESOL Methods: Changing Tracks, Challenging Trends. TESOL Quarterly, 40(1), 59-81.

Lantolf, J. P. \& Beckett, T. G. (2009). Research timeline; Sociocultural theory and second language acquisition. Language Teaching, 42(4), 459-475.

Mulryan, C.M. (1992). Student passivity during cooperative small group in mathematics. Journal of Educational Research, 85(5), 261-273.

Ohata, K. (2005). Language Anxiety from the Teacher's Perspective: Interviews with Seven Experienced ESL/EFL Teachers. Journal of Language and Learning, 3(1), 133-155.

Oxford, R. L. (1997). Cooperative learning, collaborative learning, and interaction: Three communicative strands in the language classroom. The Modern Language Journal, 81(4), 443-456.

Paran, A. (2008). The role of literature in instructed foreign language learning and teaching: An evidence-based survey. Language Teaching, 41(4), 465-496.

Roscoe, R.D. \& Chi, M.T.H. (2007). Understanding tutor learning: Knowledge-building and knowledge-telling in peer tutors' explanations and questions. Review of Educational Research, 77, 534-574.

Salomon, G. \& Globerson, T. (1989). When teams do not function the way they ought to. International journal of Educational research, 13 (1), 89-100.

Spielmann, G. \& Radnofsky, M. L. (2001). Learning Language under Tension: New directions from a qualitative study. The Modern Language Journal, 85(2), 259-278.

Svalberg, A. M-L (2007). Language awareness and language learning. Language Teaching, 40(4), 287-308.

Svalberg, A. M-L. (2009). Engagement with language: Developing a construct. Language Awareness, 18(3-4), 259-276.

Tocalli-Beller, A. (2003). Cognitive conflict, disagreement and repetition in collaborative groups: Affective and social dimensions from an insider's perspective. Canadian Modern Language Reviews 60(2), 143-172.

Tocalli-Beller, A., \& Swain, M. (2005). Reformulation: The cognitive conflict and L2 learning it generates. International Journal of Applied Linguistics, 15(1), 5-28.

Vygotsky, L. (1978). Mind in society. Cambridge, MA: Harvard University Press. 
Wright, T. \& Bolitho, R. (1993). Language awareness: A missing link in language teacher education? ELT Journal, 47(4), 292-304.

\section{APPENDIX A}

Spread of marks on the final grammar test by cohort and strand.

\begin{tabular}{lll|ll}
\hline & \multicolumn{2}{c|}{ C1 (2008-9) } & \multicolumn{2}{c}{ C2 (2009-10) } \\
\hline & \multicolumn{2}{c}{ AL } & TESOL & \multicolumn{2}{c}{ AL } & TESOL \\
\hline A (70\%+) & $37.5 \%$ & $30 \%$ & $23.3 \%$ & $5.71 \%$ \\
\hline B (60-69\%) & $36.5 \%$ & $45 \%$ & $41.18 \%$ & $37.14 \%$ \\
\hline C (50-59\%) & $25 \%$ & $20 \%$ & $29.42 \%$ & $34.29 \%$ \\
\hline D (40-49\%) & $0 \%$ & $5 \%$ & $5.88 \%$ & $17.14 \%$ \\
\hline F (below 40\%) & $0 \%$ & $0 \%$ & $0 \%$ & $5.71 \%$ \\
\hline Average score & $65.55 \%$ & $64.53 \%$ & $69.94 \%$ & $56.98 \%$ \\
\hline
\end{tabular}

The students' knowledge was not measured before the course ${ }^{2}$. The final, written test was one part of the final module assessment. As it was not standardized, one cohort's grades cannot reliably be compared to the other. The table does, however, show that while the two strands were roughly comparable in the first cohort, there was clear difference in achievement in $\mathrm{C} 2$.

\section{APPENDIX B}

Some texts used for the workshop activities, and the features they focused on

\begin{tabular}{l|l}
\hline Text & Grammar Feature \\
\hline $\begin{array}{l}\text { 'Scientific Evidence for Lucid Dreaming' from LaBerge, S. (2004) } \\
\text { A psychobiological model of dreaming. Boulder, CO: Sounds } \\
\text { True, p.19-20. }\end{array}$ & $\begin{array}{l}\text { Verb type; Clause type; Clause relations; } \\
\text { Information structure }\end{array}$ \\
\hline $\begin{array}{l}\text { 'It was, gentlemen, after a long absence' from Salih, Tayib. (1969) } \\
\text { Season of Migration to the North. Oxford: Heinemann: pp.1-3. }\end{array}$ & Tense; Aspect \\
\hline $\begin{array}{l}\text { 'The Year of Salma al-Hurra' from Maalouf, A. (1994) Leo the } \\
\text { African. London: Abacus. }\end{array}$ & Noun Phrases \\
\hline 'It must of been after midnight' from Carey, P. 'The Kelly Gang' & Punctuation; Clauses and Sentences \\
\hline 'Lamb to the slaughter' (whole text) by Dahl, R. & Modality \\
\hline 'Sophy and Toni' from Golding, W. (1979). Darkness Visible. & Adjective Phrases and Adverbials \\
London: Faber \& Faber, p.105 & Theme/Rheme structure; Nominalization \\
\hline Medecins Sans Frontiers, Dispatches 53, pp.4-5
\end{tabular}

\section{APPENDIX C}

Survey questions by theme; numbers indicate order in the survey instrument: 
General Satisfaction

12. The workshop activities were useful to me.

21 . The texts made the course more interesting.

23. Seeing the grammar in context was useful.

26. I did not learn a lot on this course.

28. What I learnt on this course will be useful to me as a teacher.

29. I am more interested in Grammar now than before the course.

Autonomy

4. I like working things out for myself.

6. I like difficult tasks; they can be an interesting challenge.

Difficulty and Cognitive Conflict

13. The workshop activities were too difficult.

22. The texts were too difficult.

24. Not having an answer key to some of the activities and exercises made me anxious.

Noticing and Concentration

1. I have often noticed and thought about how people use language.

14. During group work, I found it easy to concentrate.

Participation

3. I would describe myself as an outgoing and sociable person.

7. During group work, I prefer to listen to others.

15. I didn't participate much in the group work.

25. I learnt a lot on this course by discussing with other students.

27. I learnt a lot on this course by studying on my own.

The survey included questions on the whole course, including the lectures and VLE element but only the workshop related questions, discussed in this paper, are listed above. 